\title{
Sleep and Cognitive Function in Shift Working Police Officers: Focusing on the Night Nap
}

\author{
Yujin Hong, Sangha Lee, Ji-young Lee, Sooyeon Suh, Shift Worker Disorder Study Group \\ Department of Psychology, Sungshin Women's University, Seoul, Korea
}

교대근무 경찰공무원들의 수면 및 인지기능 실태: 야간 단수면을 중심으로

홍유진, 이상하, 이지영, 서수연

성신여자대학교 심리학과

Received May 14, 2020

Revised June 9,2020

Accepted June 23, 2020

Address for correspondence

Sangha Lee, $\mathrm{PhD}$

Department of Psychology,

Sungshin Women's University,

2 Bomun-ro 34da-gil,

Seongbuk-gu, Seoul 02844, Korea

Tel: $+82-2-920-7215$

Fax: +82-2-920-2040

E-mail: xrpsychology@gmail.com
Objectives: Currently, more than $80 \%$ of Korean police officers are assigned to a 24-hour rotating shift system. Shift workers' sleep patterns change frequently, which may result in circadian rhythm desynchrony and sleep disturbance. The goal of this study was to compare sleep and cognitive functioning in different shift types. In addition, we analyzed the difference in cognitive functioning depending on whether shift workers took a night nap prior to their night shift. Methods: A total of 278 police officers working in Seoul (mean age $45.27 \pm 9.00$ years, $88.5 \%$ male) participated, providing demographic information and completing selfreport questionnaires [Insomnia Severity Index, Epworth Sleepiness Scale, Munich ChronoType Questionnaire (Shift-work type), Patient Health Questionnaire-9]. Participants also performed the Psychomotor Vigilance Task, Trail Making Test A \& B, and Stroop Test. Results: Participants included 57 (20.5\%) day workers and $221(79.5 \%)$ shift workers. The average Insomnia Severity Index score of shift workers was significantly higher than day workers $(\mathrm{t}=-2.861, p=0.005)$. Shift workers also slept about 0.78 hours less than day workers $(\mathrm{t}=4.730, p<0.001)$. Among shift workers, $66.3 \%(\mathrm{n}=128)$ reported they took night naps prior to their night shift, sleeping on average 1.78 hours. Shift workers who took night naps had faster reaction times on the Trail Making Test A task $[\mathrm{F}(1,136)=5.741, p=0.018]$, and significantly fewer Stroop C errors $[\mathrm{F}(1,137)=5.638, p=0.019]$ than those who did not. Conclusions: Shift working police officers reported significantly worse insomnia symptoms and slept less compared to their non-shift-working counterparts. Taking a night nap improved focused and selective attention.

J Sleep Med 2020;17(2):113-121
서 론

공공의 안녕과 질서 유지 임무를 맡는 국가공무원을 경찰 공무원이라고 지칭한다. 경찰공무원은 일반 공무원과 달리 국민의 안녕과 치안 유지를 위한 특수 임무를 수행하며 일반 적으로 경찰관으로 통칭한다. ${ }^{1}$ 현재 우리나라 경찰공무원은 약 $80 \%$ 이상이 24 시간 순환교대 근무방식에 배치되어 있다. ${ }^{2}$ 교대근무자들은 수면시간이 자주 바뀌어, 이로 인해 생체 리듬 주기의 불일치 혹은 수면 교란을 경험한다. 이러한 생체

This is an Open Access article distributed under the terms of the Creative Commons Attribution Non-Commercial License (https://creativecommons.org/licenses/by-nc/4.0) which permits unrestricted non-commercial use, distribution, and reproduction in any medium, provided the original work is properly cited.
리듬의 교란은 수면 주기에 영향을 주게 되고, 불면증, 주간 졸림증, 수면의 질 저하 등의 다양한 수면장애를 유발할 수 있다. Shen 등의 연구에서는 교대근무가 생체리듬을 교란시 켜 불규칙한 수면양상을 유발하고, 수면의 질을 떨어뜨린다 고 보고하였다. ${ }^{3}$ 더불어, Ohida 등의 연구에서도 교대근무자 들이 일근근무자에 비해 주관적인 수면의 질이 유의미하게 낮았다. ${ }^{4}$ Garbarino 등이 이탈리아 경찰공무원들을 대상으로 시행한 연구에 의하면, 교대근무 환경은 수면장애에 영향을 미친다. ${ }^{5}$ 구체적으로, 교대근무자들은 일근근무자에 비해 불 면증, 과다수면(hypersomnia), 하지불안 증후군(restless legs syndrome, RLS) 혹은 주기성 사지운동 장애(periodic limb movement disorder, PLMD)를 더 많이 보고하였으며, 그 차 
이는 통계적으로 유의미하였다. Park 등이 우리나라 경찰공 무원에 대해 발표한 연구에 따르면, 교대근무 경찰공무원의 수면장애는 피로도를 높이고, 직무 만족을 저해하는 요인이 될 수 있다. ${ }^{2}$

실제로 2014년 Hong 등에 의해 발표된 자료에 따르면, 경 찰공무원 중 수면시간이 하루에 8시간 미만인 경우는 약 $75.7 \%$ 로, 대다수의 경찰공무원이 권장되는 수면시간을 충족 시키지 못하고 있었다. ${ }^{6}$ 이처럼 교대근무로 유발된 수면 부 족은 주의력 및 기억력 손상과 같은 인지기능의 손상을 야 기한다. 또한, 작업 기억, 주의, 정보 처리 속도 등의 인지기 능은 업무 수행에 중요한 역할을 하므로, 정밀하고 즉각적인 반응이 요구되는 경우에는 임시적인 인지기능의 손상도 심 각한 결과를 초래할 수 있다. ${ }^{8}$ 따라서, 긴급 상황에 민첩하게 대응해야 하는 경찰공무원의 업무 특성상 수면 부족으로 인 해 유발된 인지기능의 손상은 업무능력의 저하로도 이어질 수 있다. ${ }^{9}$

교대근무 시, 야간근무자들은 그 중에서도 특히 수면이 부 족한 것으로 보고된다. ${ }^{10-12}$ 또한, 야간 교대근무 진행 시, 시 간이 진행될수록 각성 및 업무 수행이 저하되는 경향을 보 였다. 이에 Vallières 등은 교대근무자들에게 적합하게 변형 된 수면 제한 요법을 통해, 생활 양식에 맞게 길이와 시간이 조정되고, 수면 항상성 과정을 방해하지 않는 선에서 적용된 단수면(nap)을 제안하기도 한다. ${ }^{13}$ 실제로 Takeyama 등의 연 구에 따르면, 야간 교대근무조에서 근무 중 취하는 단수면의 시간이 짧은 교대근무자들은 수면 패턴이 불규칙했으며, 주 관적인 피로도 수준도 높았다. ${ }^{14}$

Milner와 Cote의 논문에서는 단수면의 이점들에 대한 연 구들을 개관하고 있다. ${ }^{15}$ 해당 연구들에 따르면, 일반인이 낮 잠을 자는 경우, 반응 속도를 개선시키며, 교대근무자들이 낮 잠을 자는 경우, 반응 속도를 측정하는 수행에서 오류(lapses) 의 횟수를 감소시키고, 반응 속도뿐만 아니라 각성과 관련한 수행을 향상키는 효과가 있었다. 더불어, Sallinen 등은 14명 의 교대근무를 하는 남성을 대상으로 통제된 실험을 통해 야간근무의 적절한 타이밍을 실험한 결과, 야간근무 중의 단 수면은 반응시간을 단축시키고, 수행에서의 오류를 감소시 키는 등 각성도를 증진시키는 효과가 있다고 보고하였다. ${ }^{16}$ 이러한 결과는 단수면이 경찰공무원들의 인지기능을 향상시 키는 효과가 있음을 시사하며, 이는 기민한 업무 수행이 많은 경찰공무원의 업무 특성상, 업무 전반에서의 수행을 향상시 킬 수 있음을 나타낸다.

야간근무 시, 근무 전에 취하는 단수면은 야간근무로 인한 졸음 및 이로 인한 사고와 여러 건강 문제들을 방지할 수 있 다. 구체적으로, Garbarino 등이 교대근무를 하는 경찰 운전 자(police drivers)들을 대상으로 시행한 연구에 따르면, 야간 근무 전의 단수면은 시간당 $48 \%$ 의 교통 사고를 감소시켰다. ${ }^{17}$ 이러한 결과를 통해, 야간근무 시 필요로 하는 각성의 보완 및 야간근무 시의 기능 저하에 대한 대응책으로써 단수면이 효과가 있음을 알 수 있다.

본 연구에서는 경찰공무원의 인지기능을 측정하기 위하여 감각 반응 검사(Psychomotor Vigilance Task, PVT), 선 추 적 검사(Trail Making Test $\mathrm{A} \& \mathrm{~B}, \mathrm{TMT} \mathrm{A} \& \mathrm{~B})$, 스트룹 검사 (Stroop Test)를 실시하였다. PVT는 지속적 주의력과 운동 신경의 활성화를 측정하며, TMT A\&B는 주의력, 인지적 유 연성, 시각적 탐색 및 운동 기능을, 스트룹 검사는 상황에 따 른 인지능력 전환 및 반응 억제능력을 측정하는 검사이다. 경찰공무원들은 돌발적으로 발생하는 사건에 대해 민첩하게 반응하고 의사결정을 해야 하는 상황에 놓이는 경우가 많으 므로, 이러한 인지검사를 통해 기억력, 주의 집중력, 반응 속 도 등을 직접 측정하여, 그들의 업무 중 기능에 대하여 규명 하고자 하였다.

교대근무 시에 단수면을 취하는 것이 교대근무자들의 업 무 수행에 긍정적 효과들을 야기할 것임을 시사하는 연구 결 과들이 존재하긴 하지만, ${ }^{13,15-17}$ 아직까지 실험실이 아닌, 통제 되지 않은 현장에서 단수면의 효과를 살펴본 연구는 없다.

따라서 본 연구에서는 PVT, TMT A\&B, 스트룹 검사와 같 은 신경심리검사를 통해 그들의 인지기능을 분석하고, 야간 근무 전의 수면을 야간 단수면(night nap)이라고 정의하여, 야간 단수면 여부에 따른 인지기능 수준의 차이에 대해 알아 보았다. 또한, 자기보고식 질문지와 일주기 유형 선호도 질문 지(Munich ChronoType Questionnaire, MCTQ)를 통해 일 근직 경찰공무원과 교대근무 경찰공무원들의 수면에 대해 분석하였다. 특히, 교대근무자용 일주기 유형 선호도 질문지 (Munich ChronoType Questionnaire for Shift Workers, $\mathrm{MCTQ}-\mathrm{SW}$ )를 통해 일근근무자들과 교대근무자들의 중간 수면을 추출하여 일주기 유형의 차이를 살펴보았다.

\section{방 법}

\section{연구 대상}

본 연구는 2016년 6월 7일부터 11월 28일까지 약 6개월 간, 서울에서 근무하는 경찰공무원 278명을 대상으로 진행하였 다. 평균 연령은 45.27 \pm 9.00 세(범위: 22 66세)였으며, 남성 은 전체의 $88.5 \%$ 를 차지했다.

\section{연구 절차}

본 연구에서는 경찰공무원을 대상으로 수면에 대한 자기 
보고식 질문지와 다양한 영역을 측정하는 신경심리검사를 진행하였다. 연구 시행 이전에, 연구에 대한 사전 설명과 참 여 동의서 작성 과정을 거쳤으며, 성신여자대학교 생명윤리 심의위원회의 승인(SSWUIRB 2017-025)을 받았다.

통계 분석에는 SPSS version 21.0(IBM Corp., Armonk, $\mathrm{NY}, \mathrm{USA}$ )을 이용하였으며, 통계적 유의성은 $p$ 값이 0.05 미 만일 때 통계적으로 유의한 것으로 판단하였다.

\section{측정도구}

\section{자기보고식 질문지}

불면증 심각도 질문지(Insomnia Severity Index, ISI)

Bastien 등이 개발하여 Cho 등이 타당화한 한국판 불면증 심각도 질문지(Insomnia Severity Index, ISI)를 사용하였 다. ${ }^{18,19} \mathrm{ISI}$ 는 총 7 문항으로 구성되어 있으며, 지난 2주 간의 불면증 심각도, 수면에 대한 만족도, 주간 활동의 어려움 등 을 측정한다. 총점은 0 에서 28점으로 점수가 높을수록 불면 증 심각도가 높다는 것을 의미하며, 0 7점은 정상군, 8 14점 은 역치하 불면증, 15 21점은 중증도 불면증, 22 28점은 고 도 불면증으로 구분한다. 본 연구에서의 내적 일치도 계수는 0.84 였다.

주간 졸림증 질문지(Epworth Sleepiness Scale, ESS)

Johns가 개발하고 Cho 등이 타당화한 한국판 엡워스 졸림 증 질문지(Epworth Sleepiness Scale, ESS)를 사용하였다. 20,21 $\mathrm{ESS}$ 는 주간에 경험할 수 있는 다양한 상황에서의 졸림 정도 를 측정하며, 총 8 문항으로 이루어져 있다. 총점은 0 에서 24 점으로 점수가 높을수록 주간에 졸림을 심하게 느낀다는 것 을 의미한다. 11 점 이상을 주간 졸림증 위험군으로 구분하며, 본 연구에서의 내적 일치도 계수는 0.80 이었다.

일주기 유형 선호도 질문지(MCTQ)

Roenneberg 등이 개발하고, Suh 등이 타당화한 일주기 유형 선호도 질문지를 사용하였다. 22,23 해당 질문지는 실제 수면 시간과 활동 시간을 측정하여 개인의 일주기 선호 유형 (chronotype)을 파악하는데 사용되는데, 본 연구에서는 해 당 질문지의 응답을 통해 일근근무자들의 평일과 휴일의 수 면을 측정하였다.

교대근무자용 일주기 유형 선호도 질문지(MCTQ-SW)

본 연구에서는 Juda 등이 개발하고, Choi 등이 번역 및 역 번역한 교대근무자용 일주기 유형 선호도 질문지를 경찰공
무원의 주간-야간-비번-휴무의 4조 2교대 형태에 맞게 수 정하여 사용하였다. ${ }^{24,25}$ 해당 질문지는 근무일과 휴일에 따른 실제 수면 시간과 활동 시간을 측정하여 개인의 일주기 선호 유형을 파악한다. 본 연구에서는 해당 질문지에 대한 응답을 통해 교대근무자들의 수면에 대해 수집하였다. 또한, 본 연 구에서 사용한 “야간 단수면"의 변수는 해당 질문지의 야간 근무시의 수면에 대한 문항을 통해 수집되었다. "나는 단수 면을 잔다”에 대한 응답을 통해 야간 단수면의 여부를 수집 하고, "예" 라고 응답한 경우에는 이어지는 주관식 문항을 통해 구체적으로 “몇 시 몇 분부터, 몇 시 몇 분까지” 자는지 응답하도록 하여 그 시간을 측정하였다.

\section{신경심리검사}

정신운동성 주의력 검사: 감각 반응 검사(PVT)

이 검사는 Joggle Research Software(Joggle Research, Seattle, WA, USA)가 설치된 태블릿 PC(hand-held portable devices)를 통해 시행되었다. 해당 검사에서는 약 5 분 동안 화면에 랜덤하게 나타나는 자극에 빠르게 반응하는 정도를 반응시간으로 측정한다. 이를 통해 지속적 주의력(sustained attention)을 측정하게 된다. PVT는 지속적 주의력과 운동 신경의 활성화를 반영한다. ${ }^{26}$

본 연구에서는 반응속도의 감소를 보다 더 잘 반영하기 위 해 선행 논문을 참고하여 평균 반응시간의 반비례 값(mean reciprocal response time, RRT), 오류(lapses), 과실(false starts) 를 측정 지표로 하여 분석하였다. ${ }^{27}$ 이 때, 오류는 $500 \mathrm{~ms}$ 를 초 과한 반응의 횟수를, 과실은 자극이 제시되기 전의 반응 횟 수를 의미한다. ${ }^{28}$

주의 지속력 및 주의 전환 능력 검사: 선 추적 검사 (TMT A\&B)

TMT는 일련의 숫자로 구성된 원들을 순서대로 연결하는 'Part A'와 일련의 숫자와 글자로 구성된 원들을 '숫자-글자' 로 번갈아 가며 순서대로 연결하는 'Part B'의 두 단계로 구 성되어 있다..$^{2}$ 이를 통해 주의의 속도, 추적, 분할 주의 능력, 인지적 유연성, 시각적 탐색 및 운동 기능을 평가한다.

집행기능 검사: 색채-단어 스트룹 검사(Stroop Test)

스트룹 검사는 상황에 따라서 개인이 인지능력을 전환하 고 불필요한 반응을 억제하는 능력을 보는 검사이다. 30,31 단 어읽기, 색채읽기, 색채-단어 간섭의 세 조건으로 구성되어 있다. 첫 번째 단어조건에서는 색채 이름이 쓰인 단어를 읽게 한다. 색채조건에서는 인쇄된 색채의 이름을 말하도록 한다. 
마지막으로 색채-단어 간섭조건에서는 색채를 의미하는 단 어와 그 단어가 나타내는 색이 다르며, 단어가 아닌 인쇄된 색채에 반응할 것을 요구한다.

\section{결 과}

\section{인구통계학적 요인}

연구 대상자 278명은 교대근무 여부에 따라 57명(20.5\%)의 일근근무자와, 221 명(79.5\%)의 교대근무자로 구성되었다. 본 연구에 참여한 교대근무자들은 '주간-야간-비번-휴무' 4조 2교대 형태로 근무하였다.

교대근무 여부와 성별, 계급, 결혼상태 간의 연관성을 알아 보기 위해 교차분석을 실시하였다. 분석 결과, 교대근무 여부 와 성별 간의 연관성이 통계적으로 유의미하였다 $\left(\chi^{2}=33.523\right.$, $p<0.001)$. 계급과 결혼 상태의 경우, 5 미만의 기대 빈도가 전체 항(cell)의 $20 \%$ (각각 $33.3 \%, 60.0 \%$ )를 차지하여, Pearson 카이제곱 검정이 아닌 Fisher의 정확검정으로 유의확률을 파악하였다. Fisher의 정확검정 결과, 교대근무 여부와 계급 간의 연관성이 통계적으로 유의미하였다 $(p<0.001)$.

더불어, 교대근무 여부에 따른 나이, 근속연수의 차이를 알 아보기 위해 $\mathrm{t}$ 검정을 실시하였다. 분석 결과, 교대근무자들은 일근근무자에 비해 통계적으로 유의미한 수준에서 나이가 많았으며 $(\mathrm{t}=-3.934, p<0.001)$, 근속연수도 더 길었다 $(\mathrm{t}=-2.632$, $p=0.010)$. 연구 대상자에 대한 자세한 내용은 Table 1에 기술 하였다.

\section{교대근무 여부에 따른 임상 지표의 차이}

교대근무 여부에 따른 불면증(ISI), 주간졸림증(ESS)에 대 한 임상 지표 결과 차이를 $\mathrm{t}$ 검정을 통해 분석하였다. 분석 결과, 교대근무자의 평균 ISI 점수는 8.82( \pm 5.68$)$ 점으로 6.86 ( \pm 4.31 점인 일근근무자의 평균 ISI 점수에 비해 유의미하게 높았다 $(\mathrm{t}=-2.861, p=0.005)$. 교대근무자의 $\mathrm{ESS}$ 점수는 6.59 ( \pm 3.43$)$ 점으로, 7.26( \pm 4.09$)$ 점에 비해 0.67점가량 낮았으나, 그 차이가 통계적으로 유의미하지는 않았다. 자세한 내용은 Table 2에 제시하였다.

\section{MCTQ및 MCTQ-SW의 주요 지표 분석}

MCTQ 및 MCTQ-SW의 응답을 통해 수면 시작 시각(sleep onset, $\mathrm{SO}$ )과 수면이 끝나는 시각(sleep end, SE)을 파악하여, 이를 통해 수면 기간(sleep duration, $\mathrm{SD}=\mathrm{SE}-\mathrm{SO}$ )과 중간수 면(mid sleep, $\mathrm{MS}=\mathrm{SO}+\mathrm{SD} / 2)$ 을 계산하였다. 사람들은 중간 수면 시점에서 가장 깊은 잠에 들며, 중간수면을 바탕으로 시간 기반 일주기 유형인 교정된 휴일 중간수면(mid-sleep
Table 1. Demographic information $(n=278)$

\begin{tabular}{lccc}
\hline \multicolumn{1}{c}{ Variables } & $\begin{array}{c}\text { Day worker } \\
(\mathrm{n}=57,20.5 \%)\end{array}$ & $\begin{array}{c}\text { Shift-worker } \\
(\mathrm{n}=221,79.5 \%)\end{array}$ & $p$ \\
\hline Sex & & & $<0.001^{* * *}$ \\
$\quad$ Male & $38(66.7)$ & $208(94.1)$ & \\
Female & $19(33.3)$ & $13(5.9)$ & \\
Age (years) & $41.19 \pm 9.72$ & $46.32 \pm 8.52$ & $<0.001^{* * *}$ \\
Rank & & & $<0.001^{* * *}$ \\
Constable & $5(8.8)$ & $20(9.0)$ & \\
Corporal & $9(15.8)$ & $7(3.2)$ & \\
Sergeant & $12(21.1)$ & $46(20.8)$ & \\
Lieutenant & $23(40.4)$ & $143(64.7)$ & \\
Inspector & $5(8.8)$ & $5(2.3)$ & \\
Etc. & $3(5.3)$ & $0(0)$ & \\
Years of service & $16.23 \pm 10.56$ & $20.24 \pm 8.93$ & $0.010^{*}$ \\
Marital status & & & 0.214 \\
Single & $14(24.6)$ & $29(13.1)$ & \\
Married & $43(75.4)$ & $187(84.7)$ & \\
Divorced & $0(0)$ & $4(1.8)$ & \\
Bereavement & $0(0)$ & $1(0.5)$ & \\
\hline Pa are & & & \\
\hline
\end{tabular}

Data are presented as $\mathrm{n}(\%)$ or mean \pm SD. Statistical analysis for gender was done by Pearson's chi-square test; analysis for rank, marital status was done by Fisher's exact test; and analysis for age, years of service was done by t-test. ${ }^{*} p<0.05,{ }^{* * *} p<0.001$

Table 2. Differences in clinical variables depending on work type $(\mathrm{n}=278)$

\begin{tabular}{cccc}
\hline Variables & Day worker $(\mathrm{n}=57)$ & Shift-worker $(\mathrm{n}=221)$ & $p$ \\
\hline ISI & $6.86 \pm 4.31$ & $8.82 \pm 5.68$ & $0.005^{* *}$ \\
ESS & $7.26 \pm 4.09$ & $6.59 \pm 3.43$ & 0.466 \\
\hline
\end{tabular}

Data are presented as mean \pm standard deviation. Statistical analysis was done by t-test. ${ }^{* *} p<0.01$. ISI: Insomnia Severity Index, ESS: Epworth Sleepiness Scale

time on free days corrected for sleep debt accumulated over the work week, MSFsc)을 측정할 수 있다..$^{25}$

Choi 등의 연구를 바탕으로, 연구 참여자들을 교대근무와 일근근무자로 나누어, 중간수면 및 교정된 휴일 중간수면 (MSFsc)을 측정하였다. ${ }^{25}$ 휴일 수면이 근무일보다 더 길다면 근무일의 부족한 수면시간을 보충하는 것이기 때문에 평소 수면부족분을 보정한 교정된 중간수면으로 계산한다. 일근 근무자의 경우에는 휴일 중간수면(mid-sleep time on free days, MSF)에서 평일과 휴일 간 수면시간의 차이를 보정한 교정된 휴일 중간수면으로 산출하였다. 또한 교대근무자의 경우에는 휴무 시 중간수면에서 근무일(주간, 야간, 비번)과 휴무 간 수면시간의 차이를 보정된 교정된 중간수면으로 산 출하였다.

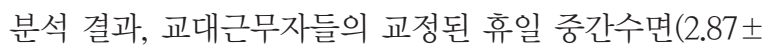


$3.45 \mathrm{~h} ; 24$-h clock)은 일근근무자들보다 약 한 시간 더 앞 당겨져 있었다. 자세한 내용은 Table 3에 제시하였다.

\section{교대근무 여부에 따른 평균 수면시간의 차이}

$\mathrm{MCTQ}$ 및 MCTQ-SW의 응답 결과, 참여자들의 개인 평 균 수면시간은 5.65( \pm 1.09$)$ 시간으로 보고되었다. 교대근무 자들의 경우, $\mathrm{MCTQ}-\mathrm{SW}$ 를 통해 주간, 야간, 비번, 휴무 시 각각의 총 수면시간을 파악한 후 이에 대한 평균을 산출하였 다. 교대근무 여부에 따라 개인 평균 수면시간에 차이가 있는 지 알아보기 위해 $\mathrm{t}$ 검정을 시행하였는데, 교대근무자 $(5.45 \pm$ 1.06 시간)들이 일근근무자( $6.23 \pm 0.99$ 시간)들에 비해 약 0.78 시간 적은 수면 시간을 보고하였고, 통계적으로 유의미했다 $(\mathrm{t}=4.730, p<0.001)$. 자세한 내용은 Table 4에 제시하였다.

\section{교대근무 여부에 따른 인지기능 결과 차이}

연령과 성별을 공변인으로 설정하여 신경심리검사 수행에

Table 3. Key parameters of all participants assessed by the MCTQ and MCTQ-SW $(n=278)$

\begin{tabular}{|c|c|c|c|}
\hline \multirow[b]{2}{*}{ Variable } & \multicolumn{3}{|c|}{ Mid-sleep time (h; 24-h clock) } \\
\hline & $\begin{array}{l}\text { Day worker } \\
\quad(\mathrm{n}=57)\end{array}$ & \multicolumn{2}{|c|}{$\begin{array}{l}\text { Shift-worker } \\
\quad(n=221)\end{array}$} \\
\hline MSFsc & $3.80 \pm 0.95$ & \multicolumn{2}{|c|}{$2.87 \pm 3.45$} \\
\hline Mid-sleep of work days & $3.18 \pm 0.63$ & \multicolumn{2}{|r|}{-} \\
\hline Mid-sleep of free days & $4.19 \pm 1.23$ & \multicolumn{2}{|r|}{-} \\
\hline Mid-sleep of day duty & - & \multicolumn{2}{|c|}{$3.24 \pm 1.71$} \\
\hline Mid-sleep of night duty & - & \multicolumn{2}{|c|}{$12.07 \pm 3.03$} \\
\hline Mid-sleep of off duty & - & \multicolumn{2}{|c|}{$3.95 \pm 2.20$} \\
\hline Mid-sleep of day off & - & \multicolumn{2}{|c|}{$2.82 \pm 1.66$} \\
\hline \multicolumn{4}{|c|}{$\begin{array}{l}\text { Data are presented as mean } \pm \text { standard deviation. MCTQ: Munich } \\
\text { ChronoType Questionnaire, MCTQ-SW: Munich ChronoType } \\
\text { Questionnaire for Shift Workers MSFsc: Mid-sleep time on free } \\
\text { days corrected for sleep debt accumulated over the work week }\end{array}$} \\
\hline Table 4. Differen & leep tim & ach & 78) \\
\hline \multirow[b]{2}{*}{ Variable } & \multicolumn{2}{|c|}{ Total sleep time (h) } & \multirow[b]{2}{*}{$p$} \\
\hline & $\begin{array}{l}\text { Day worker } \\
\quad(\mathrm{n}=57)\end{array}$ & $\begin{array}{l}\text { Shift-worker } \\
\quad(n=221)\end{array}$ & \\
\hline Mean of total sleep time & $6.23 \pm 0.99$ & $5.45 \pm 1.06$ & $<0.001^{* * *}$ \\
\hline Work days & $5.89 \pm 0.96$ & - & \\
\hline Free days & $7.03 \pm 1.47$ & - & \\
\hline Day duty & - & $6.10 \pm 1.77$ & \\
\hline Night duty & - & $2.88 \pm 1.38$ & \\
\hline Off duty & - & $7.04 \pm 1.63$ & \\
\hline Day off & - & $5.81 \pm 1.26$ & \\
\hline
\end{tabular}

Data are presented as mean \pm standard deviation. Statistical analysis for the mean of total sleep time was done by t-test. ${ }^{* * *} p<0.001$
미치는 영향을 통제한 후 근무 형태에 따라 신경심리검사 수 행에 차이가 있는지를 살펴보기 위해 공분산분석을 실시하 였다. 그 결과, PVT, TMT, 스트룹 검사 모두에서 두 집단 간 통계적으로 유의미한 차이는 발견하지 못하였다. 다만, 일근 근무자(3.87 \pm 0.54$)$ 가 교대근무자(3.79 \pm 0.59$)$ 보다 PVT RRT 가 더 빠른 경향이 있었다. 세부적인 검사 결과는 Table 5 에 제시하였다.

\section{야간 단수면 여부에 따른 신경심리검사 결과 차이}

본 연구에서 정의한 야간 단수면이란, 교대근무자들이 야 간근무 전 취하는 수면으로, 야간근무 퇴근 후 돌아와 취하는 수면과는 구분된다. 본 연구에서 야간근무를 한 교대근무자 193 명 중 66.3\%(n=128)가 야간 단수면을 취한다고 응답하였 으며, 그들은 평균 $1.78( \pm 0.67)$ 시간 잤다고 응답하였다. 또한, 야간근무 퇴근 후의 아침 수면은 평균 2.88( \pm 1.38 )시간이었 다. 야간 단수면의 여부에 따른 신경심리검사 결과의 차이를 분석하기 위해 이원분산분석을 시행하였다. 분석 결과, 야간 단수면을 취한 집단의 경우, 그렇지 않은 집단보다 TMT-A의 값이 유의미하게 낮았으며 $[\mathrm{F}(1,136)=5.741, p=0.018]$, Stroop $\mathrm{C}$ error의 값 또한 유의미하게 낮았다 $[\mathrm{F}(1,137)=5.638, p=$ 0.019]. 낮은 TMT-A값과 Stroop C error값은 높은 초점 주 의력 및 선택적 주의력을 시사한다. ${ }^{32}$ 자세한 내용은 Table 6 에 제시하였다.

\section{고 찰}

교대근무자들은 일주기 패턴이 자주 변화하는 생활 속에

Table 5. Differences in neuropsychological assessments between groups $(n=278)$

\begin{tabular}{lccc}
\hline \multicolumn{1}{c}{ Variables } & Day worker $(\mathrm{n}=57)$ & Shift-worker $(\mathrm{n}=221)$ & $p$ \\
\hline PVT & & & \\
RRT & $3.87 \pm 0.54$ & $3.79 \pm 0.59$ & 0.28 \\
Lapses & $6.27 \pm 5.27$ & $5.98 \pm 8.11$ & 0.97 \\
False starts & $0.81 \pm 1.94$ & $0.80 \pm 1.55$ & 0.59 \\
TMT & & & \\
TMT-A & $29.81 \pm 10.15$ & $32.42 \pm 12.15$ & 0.72 \\
TMT-B & $73.77 \pm 35.13$ & $88.25 \pm 48.62$ & 0.67 \\
Stroop & & & \\
Color-word & $51.00 \pm 12.51$ & $54.17 \pm 13.18$ & 0.75 \\
C error & $1.19 \pm 2.38$ & $1.01 \pm 2.54$ & 0.23 \\
\hline
\end{tabular}

Data are presented as mean \pm standard deviation. Statistical analysis was done by ANCOVA. Age and sex were controlled in this statistical analysis. PVT: Psychomotor Vigilance Task, TMT: Trail Making Test, RRT: mean reciprocal response time (The higher RRT score implies the faster response time) 
Table 6. Differences in neuropsychological assessments in shift workers who take night naps $(n=193)$

\begin{tabular}{lccc}
\hline Variables & $\begin{array}{c}\text { Shift workers } \\
\text { with night nap } \\
(\mathrm{n}=128)\end{array}$ & $\begin{array}{c}\text { Shift workers } \\
\text { without night nap } \\
(\mathrm{n}=65)\end{array}$ & $p$ \\
\hline PVT & $3.86 \pm 0.56$ & $3.78 \pm 0.59$ & 0.073 \\
$\quad$ RRT & $5.13 \pm 6.95$ & $6.02 \pm 8.57$ & 0.221 \\
Lapses & $0.74 \pm 1.30$ & $0.95 \pm 2.00$ & 0.515 \\
False starts & & & \\
TMT & $32.21 \pm 10.53$ & $33.64 \pm 16.36$ & $0.018^{*}$ \\
TMT-A & $88.80 \pm 46.16$ & $93.46 \pm 59.38$ & 0.456 \\
TMT-B & & & \\
Stroop & $53.79 \pm 12.80$ & $54.57 \pm 14.56$ & 0.158 \\
Color-word & $0.73 \pm 1.35$ & $1.66 \pm 4.07$ & $0.019^{*}$ \\
Stroop C error & & & \\
\hline
\end{tabular}

Data are presented as mean \pm standard deviation. Statistical analysis was done by two-way ANOVA. Sex, age, total sleep time, NAWk1 (neuropsychological start time-wake time) were controlled in this statistical analysis. ${ }^{*} p<0.05$

서 생리적 리듬 주기가 파괴되고, ${ }^{33}$ 수면 부족이나 수면 주기 의 변화를 감수하면서 근무를 하기 때문에, 피로의 증가, 불 면증이나 과다수면과 같은 문제가 발생할 수 있다. ${ }^{34}$ 야간근 무는 수면-각성주기에 큰 영향을 줌으로써 체온, 각성시간, 피로도, 정신적 수행능력에 악영향을 줄 수 있는데 ${ }^{35}$ 특히 주 간근무와 야간근무를 며칠 간격으로 반복하게 되기 때문에 일주기리듬(circadian rhythm)의 교란가능성과 적응의 어려 움이 가중된다. ${ }^{36}$ 본 연구는 경찰공무원들의 교대근무 형태와 수면을 현장에서 조사하여, 단수면이 인지기능에 긍정적 영 향을 최초로 보여준 최초의 연구이다.

교대근무 경찰공무원의 수면과 인지기능의 양상을 조사한 본 연구에서는 교대근무자가 일근근무자들에 비해 유의미하 게 짧은 총 수면시간과 높은 불면증 심각도를 가지고 있음 이 확인되었다. 불면증은 입면의 어려움과 더불어 조기 기상 혹은 수면유지의 어려움이 특징적인 양상으로 나타나는데, $\mathrm{MCTQ}$ 를 활용하여 수면시간을 조사하는 경우 수면일지나 액티그래피(actigraphy)를 사용할 때와는 달리 입면 후 각성 시간(wake after sleep onset, WASO)이 측정되지 않기 때문 에 실제 교대근무자들의 총 수면시간은 이보다 더 적을 것 으로 예상된다.

교대근무로 인한 낮은 수면의 양과 질로 인해 일근근무자 들에 비해 유의미하게 높을 것이라고 예상했던 $\mathrm{ESS}$ 의 경우, 교대근무자의 점수는 $6.59( \pm 3.43)$ 점으로, 일근근무자의 점수 인 7.26( \pm 4.09$)$ 점에 비해 0.67점가량 낮았다. 유사한 결과를 보여준 Garbarino 등의 연구에서도 논의된 바와 같이, ${ }^{5} \mathrm{ESS}$ 는 주간 졸림을 “주관적”으로 평가하기 때문에 교대근무자
들은 스트레스가 많은 업무 특성 및 책임감으로 인해 자신의 졸림을 과소평가했을 가능성이 있다. 또한, 높은 기민성이 유 지되는 교대근무 업무 특성상 졸림을 극복했을 가능성도 배 제할 수 없다.

국내에서는 주로 간호사 등을 대상으로 한 연구에서 교대 근무로 인한 불규칙한 생활패턴과 불면증상의 높은 상관이 보고되었다. ${ }^{37}$ 의료종사자들을 중심으로 보고된 교대근무가 불면증의 위험요인으로서 작용할 가능성이 높다는 사실은 경찰공무원을 대상으로 한 본 연구에서도 유사하게 확인되 었다. 이는 경찰공무원들 중 대부분이 교대근무로 인한 불규 칙한 생활패턴으로 수면문제를 경험하고, 이로 인한 어려움 이 있는 것으로 보고한다는 선행 연구 결과를 뒷받침한다. ${ }^{38}$ 또한, 이는 Garbarino 등이 교대근무자들이 일근근무자에 비해 불면증 유병률이 약 $10 \% \mathrm{p}$ 높고, 교대근무 환경이 불면 증과 같은 수면장애에 영향을 미친다고 언급한 것과도 일치 하는 결과다.

수면 부족 및 자주 변화하는 수면 패턴으로 인해 교대근무 자들이 일근근무자들에 비해 인지기능에서 유의미한 저하가 있을 것이라고 예측한 것과 달리, 본 연구에서는 교대근무자 와 일근근무자 간 인지기능의 차이에서 유의미한 결과를 확 인하지 못하였다. Rouch 등의 연구에 따르면, 교대근무 기 간이 길수록 인지기능 점수가 낮았으며, 4년 이내에 교대근 무 이력이 없는 집단이, 있는 집단에 비해 인지기능의 점수가 더 높았다. ${ }^{39}$ 본 연구에서는 교대근무 여부에 대한 확인 후, 최근의 교대근무 이력, 교대근무 지속 기간과 같은 구체적인 지표 수집은 이루어지지 않았다. 따라서 추후 연구에서는 교 대근무 정보에 대해 좀 더 면밀히 파악하여 분석 시 활용해 볼 필요가 있다.

본 연구에서 사용한 $\mathrm{MCTQ}$ 및 $\mathrm{MCTQ}-\mathrm{SW}$ 는 각각 주중과 주말의 수면-각성 양상을 측정한다. 이를 통해 가장 깊게 잠 이 드는 중간수면을 계산할 수 있으며, 이를 바탕으로 평일과 휴일에 수면시간이 달라짐으로써 생기는 사회적 시차(social jet lag)도 추출할 수 있다. ${ }^{25}$ 분석 결과, 야간근무시의 중간수

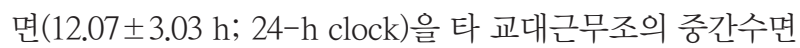
과 비교하였을 때, 휴무시의 중간수면(2.82 $\pm 1.66 \mathrm{~h} ; 24-\mathrm{h}$ clock)과 약 9.25시간으로 가장 큰 차이를 보였다. 이는 야간 근무가 잦을 경우 사회적 시차가 증가할 수 있으며, 나아가 일상생활에서의 수면에 대한 어려움 또한 악화될 수 있음을 시사한다. 따라서 야간근무 시에는 근무 전에 취하는 단수면 뿐만 아니라, 근무 후에 취하는 수면에도 각별한 주의가 필 요하다.

한편, 본 연구에는 야간 교대근무 전 취하는 수면을 야간 단수면이라고 정의하고, 야간 단수면 여부에 따른 인지기능 
의 차이를 분석했다는 점에서 국내 여타 연구들과의 차별성 을 가진다. 야간 단수면은 야간근무 후의 수면과는 구분되는 개념으로, 본 연구에서 '주간-야간-비번-휴무' 형태의 4 조 2 교대근무를 하는 경찰공무원의 경우, 야간근무 전 평균적으 로 1.78 시간 낮잠을 취하는 것으로 조사되었다. 야간 단수면 을 취한 집단의 경우, 그렇지 않은 집단에 비하여 TMT-A값 이 유의미하게 낮았으며, Stroop C error의 값 또한 유의미 하게 낮았다. 낮은 TMT-A값과 Stroop C error값은 높은 초 점 주의력 및 선택적 주의력을 시사한다. ${ }^{32}$ 이는 Sakai 등과 Purnell 등의 연구에서 예방적 야간 단수면이 각성을 유지시 키고 야간근무의 수행을 향상시킨다고 보고한 것과 일치하 는 결과로 해석된다. ${ }^{40,41}$ Pilcher 등이 진행한 연구에 따르면, 야간근무는 수면의 길이를 감소시키며, 다른 교대근무 형태 보다 수면 길이에 가장 해로운 영향을 미친다. ${ }^{11}$ 따라서 야간 근무 시의 수면에는 본 연구에서 논의된 야간 단수면과 같은 방법들을 제안하는 등, 다른 교대근무 형태로 근무할 때보다 수면에 대해 더욱 면밀히 대처할 방안들을 고안해야 할 필 요가 있다.

Sasaki 등은 야간 단수면의 효용을 인정하면서도, 야간근 무 직전의 수면이 자칫 깊은 잠을 유도하기 때문에 야간근무 중 단수면을 취하는 것이 더 효과적일 가능성을 언급하고 있 으나 이러한 야간근무 중 단수면은 보편적이지 않다는 점과, 근무 중에 수면을 취할 시 수면관성으로 인한 위험요인의 증 가도 지적되고 있다. ${ }^{42}$ 또한, Vallières 등은 불면증을 호소하 는 교대근무자를 위해 수면제한기법과 단수면을 활용한 행 동치료기법을 제안한 바 있으나, ${ }^{13}$ 이는 불면증 치료를 위한 개인치료시간의 확보와 충분한 치료회기를 확보해야 한다 는 제한점이 있다. 활용의 관점에서는 야간근무 전 단수면과 카페인 섭취를 함께 진행했을 때 교대근무자들의 인지기능 이 높은 수준으로 유지된다는 Bonnet과 Arand의 보고가 일 선 경찰서에서 수용가능한 대안을 수립하는 것에 참조가 될 수 있다. ${ }^{43}$ 야간 단수면의 효과에 대한 선행연구들의 방법론 적 차이와 개인차로 인해 일반적인 지침을 수립하는 것은 어 려움이 있음에도 야간근무로 인한 경찰공무원의 수면문제와 건강상의 문제를 개선하는 것에 야간 단수면이 유용한 방법 이라는 것은 자명해 보인다. ${ }^{44}$ Takeyama 등은 야간 단수면 을 현장에 도입하기 전에 고려해야 할 요소로 1) 야간 단수 면으로 인한 유익뿐만 아니라 수면관성 등의 역효과 또한 충분히 근무자에게 전달되어야 할 것, 2) 단수면의 시작시간 과 지속시간, 3) 쾌적한 환경, 4) 관리자의 협조 등을 제안하 고 있다. ${ }^{44}$ 따라서 추후 교대근무 경찰공무원을 위한 개입으 로 야간 단수면을 도입할 때에는 대상자 개인에 대한 교육 뿐만 아니라 근무 일정 조율, 수면 시설 확보와 같은 종합적
인 정책이 함께 고려되어야 할 것이다.

본 연구의 제한점 및 후속연구를 위한 제언은 다음과 같다. 먼저 본 연구는 서울시 한 개 경찰서를 선정하여 연구를 진행 하였기에, 이를 전체 경찰공무원들의 결과로 일반화하는 데 에는 한계가 있다. 이에 따라 추후 연구에서는 더 다양한 지 역에서, 보다 큰 규모의 경찰공무원을 대상으로 세분화한 실 태조사가 이루어져야 할 필요가 있다.

또한, 본 연구 표본의 성별은 남성이 $88.5 \%$ 로, 남성에 다소 치중되어 있다. 경찰공무원이라는 직업 특성상, 남성이 여성 에 비해 많은 비율을 차지 하고 있는 것은 사실이다. 다만, 본 연구에서 파악한 수면 및 정신 건강, 인지기능에 대한 분석 결과가 성별이라는 변수에 따른 차이가 있을 수 있으므로, 추후 연구에서는 여성의 표본을 추가해 볼 필요가 있다. 따 라서, 추가적인 여성 표본 모집을 바탕으로 한 통계적 비교 분석의 필요성이 제기된다.

더불어, 본 연구는 제한된 연구 기간 내에 한시적으로 경찰 공무원의 정신건강 및 수면에 대한 실태를 조사하였다는 한 계가 있다. 경찰 집단의 전반적인 어려움에 대해서 더욱 깊게 파악하기 위해서는, 추후 연구를 통해 장기간 추적하며 조사 해야 할 필요가 있다.

또한, 본 연구에서 경찰공무원들의 총 수면시간은 $\mathrm{MCTQ}$ 및 $\mathrm{MCTQ}-\mathrm{SW}$ 로 측정되어 WASO가 측정되지 않았다는 한 계가 있다. 이에 총 수면시간이 과대추정 되었을 가능성을 배 제할 수 없다. Lichstein 등의 연구에 따르면, 액티그래피와 수면다원검사(polysomnography)를 통해 각각 측정된 총 수 면시간과 입면 후 각성시간에는 통계적으로 유의미한 차이 가 나타나지 않았다..$^{45}$ 이에, 액티그래피는 불면증을 예측하 기에 신뢰성 있는 도구로 볼 수 있다. 따라서 후속 연구에서 는 액티그래피를 통한 수면 정보 수집으로 더욱 정밀한 수 면지표를 수집할 것을 제안한다.

본 연구에서는 연구 특성상 참여자의 교대근무 여부 및 교 대근무 시간에 관계없이 동일한 평가 시간대(10:00 16:00)에 신경심리검사가 이루어졌다. 따라서 본 연구에서는 야간 단 수면이 그 날의 야간근무에 미치는 영향을 직접적으로 확인 했다기보다는, 근무 전반에서의 인지기능의 차이를 보았다 고 해석할 수 있다. 이에 추후 연구에서는 교대근무 여부 및 시간에 따라 검사 시간을 지정하여 일관적인 시간대에 신경 심리검사를 진행한다면, 더욱 면밀한 검사 결과 해석이 가능 할 것으로 보인다.

추후 연구에서는 수면 및 인지기능의 실태를 파악하는 것 에서 한 걸음 더 나아가, 이를 치료적으로 개선할 방안에 대 해서도 충분한 논의가 이루어져야 할 것이다. 경찰 집단은 보수적이고 책임감이 강조되는 조직 문화를 가지고 있다. 이 
러한 환경 내에서 생활하기 때문에, 경찰공무원들은 개인이 자신의 정신 건강 및 수면에 대한 어려움을 파악하고 이를 드러내 변화를 시도하거나 도움을 구하기 어려운 구조에 놓 여 있다고 보아도 무방하다. 따라서, 추후 연구에서는 교대 근무자들을 포함한 전반적인 경찰공무원들의 정신 건강 및 수면 문제를 꾸준히 검진하고, 본 연구에서 논의된 야간 단수 면을 비롯한 다양한 해결책을 논의하여 이를 제도적으로도 구축하여야 할 필요가 있다.

\section{Acknowledgments}

This work was supported by the Korean National Police Agency (GRNT2016050007) and Ezwellness (Employee Assistance Program).

\section{Conflicts of Interest}

The authors have no potential conflicts of interest to disclose.

\section{ORCID iDs}

Yujin Hong

Sangha Lee

Ji-young Lee

Sooyeon Suh

https://orcid.org/0000-0002-9487-3659

https://orcid.org/0000-0002-7042-2052

https://orcid.org/0000-0002-5722-1010

https://orcid.org/0000-0003-0644-8634

\section{Author Contributions}

Conceptualization: Sooyeon Suh, Sangha Lee. Data curation: Ji-young Lee, Sooyeon Suh, Sangha Lee. Formal analysis: Yujin Hong, Sooyeon Suh. Investigation: Sooyeon Suh, Ji-young Lee, Yujin Hong. Methodology: Sooyeon Suh, Sangha Lee, Ji-young Lee, Yujin Hong. Supervision: Sangha Lee, Sooyeon Suh. Writing-original draft: Yujin Hong. Writing-review \& editing: Sangha Lee, Sooyeon Suh, Yujin Hong.

\section{REFERENCES}

1. Shin HG, Park YJ, Ahn SR, et al. [Dictionary of police science]. Seoul: Bobmunsa. 2012

2. Park JS, Choi ER. A study on relationships between sleep disorder, fatigue and job stress in police shift-workers. Police Sci J 2010;5:25-53. https://doi.org/10.16961/polips.2010.5.1.25.

3. Shen J, Botly LC, Chung SA, Gibbs AL, Sabanadzovic S, Shapiro CM. Fatigue and shift work. J Sleep Res 2006;15:1-5. https://doi.org/10.1111/ j.1365-2869.2006.00493.x.

4. Ohida T, Kamal A, Sone T, et al. Night-shift work related problems in young female nurses in Japan. J Occup Health 2001;43:150-156. https:// doi.org/10.1539/joh.43.150.

5. Garbarino S, De Carli F, Nobili L, et al. Sleepiness and sleep disorders in shift workers: a study on a group of Italian police officers. Sleep 2002; 25:642-647. https://doi.org/10.1093/sleep/25.6.642.

6. Hong JH, Lee S-W. A study on the prevalence and influencing factors of metabolic syndrome among police officers. J Korean Soc Occup Environ Hyg 2014;24:566-577. https://doi.org/10.15269/JKSOEH.2014.24.4.566.

7. Akerstedt T, Wright KP Jr. Sleep loss and fatigue in shift work and shift work disorder. Sleep Med Clin 2009;4:257-271. https://doi.org/10.1016/ j.jsmc.2009.03.001.

8. Ansiau D, Wild P, Niezborala M, Rouch I, Marquié JC. Effects of working conditions and sleep of the previous day on cognitive performance. Appl Ergon 2008;39:99-106. https://doi.org/10.1016/j.apergo.2007.01.004.

9. Choi ER, Kim JK. A study about effects of police officers' leisure activity on job satisfaction and quality of life. Police Sci J 2011;6:65-86. https://doi.org/10.16961/polips.2011.6.2.65.

10. Mitler MM, Miller JC, Lipsitz JJ, Walsh JK, Wylie CD. The sleep of long-haul truck drivers. N Engl J Med 1997;337:755-761. https://doi. org/10.1056/NEJM199709113371106.

11. Pilcher JJ, Lambert BJ, Huffcutt AI. Differential effects of permanent and rotating shifts on self-report sleep length: a meta-analytic review. Sleep 2000;23:155-163. https://doi.org/10.1093/sleep/23.2.1b.

12. Park YM, Matsumoto PK, Seo YJ, Cho YR, Noh TJ. Sleep-wake behavior of shift workers using wrist actigraph. Psychiatry Clin Neurosci 2000; 54:359-360. https://doi.org/10.1046/j.1440-1819.2000.00714.x.

13. Vallières A, Roy M, Bastille-Denis E, Claveau S, Simon T. Exploring a behavioural therapy for insomnia in shift workers. J Sleep Disord Ther 2015;4:1000202. https://doi.org/10.4172/2167-0277.1000202.

14. Takeyama $\mathrm{H}$, Itani $\mathrm{T}$, Tachi $\mathrm{N}$, et al. Effects of shift schedules on fatigue and physiological functions among firefighters during night duty. Ergonomics 2005;48:1-11. https://doi.org/10.1080/00140130412331303920.

15. Milner CE, Cote KA. Benefits of napping in healthy adults: impact of nap length, time of day, age, and experience with napping. I Sleep Res 2009;18:272-281. https://doi.org/10.1111/j.1365-2869.2008.00718.x.

16. Sallinen $M$, Härmä $M$, Akerstedt T, Rosa R, Lillqvist O. Promoting alertness with a short nap during a night shift. J Sleep Res 1998;7:240-247. https://doi.org/10.1046/j.1365-2869.1998.00121.x.

17. Garbarino S, Mascialino B, Penco MA, et al. Professional shift-work drivers who adopt prophylactic naps can reduce the risk of car accidents during night work. Sleep 2004;27:1295-1302. https://doi.org/10.1093/ sleep/27.7.1295.

18. Bastien CH, Vallières A, Morin CM. Validation of the Insomnia Severity Index as an outcome measure for insomnia research. Sleep Med 2001; 2:297-307. https://doi.org/10.1016/s1389-9457(00)00065-4.

19. Cho YW, Song ML, Morin CM. Validation of a Korean version of the Insomnia Severity Index. J Clin Neurol 2014;10:210-215. https://doi. org/10.3988/jcn.2014.10.3.210.

20. Johns MW. A new method for measuring daytime sleepiness: the Epworth sleepiness scale. Sleep 1991;14:540-545. https://doi.org/10.1093/ sleep/14.6.540.

21. Cho YW, Lee JH, Son HK, Lee SH, Shin C, Johns MW. The reliability and validity of the Korean version of the Epworth sleepiness scale. Sleep Breath 2011;15:377-384. https://doi.org/10.1007/s11325-010-0343-6.

22. Roenneberg T, Wirz-Justice A, Merrow M. Life between clocks: daily temporal patterns of human chronotypes. J Biol Rhythms 2003;18:8090. https://doi.org/10.1177/0748730402239679.

23. Suh S, Kim SH, Ryu H, Choi SJ, Joo EY. Validation of the Korean Munich chronotype questionnaire. Sleep Breath 2018;22:773-779. https:// doi.org/10.1007/s11325-017-1609-z.

24. Juda M, Vetter C, Roenneberg T. The Munich ChronoType Questionnaire for shift-workers (MCTQShift). J Biol Rhythms 2013;28:130-140. https://doi.org/10.1177/0748730412475041.

25. Choi SJ, Suh SY, Joo EY. Assessing sleep-wake pattern and chronotype with the Korean Munich chrono type for shift-workers in shift working nurses. J Sleep Med 2017;14:23-35. https://doi.org/10.13078/jsm.17004.

26. Dinges DF, Powell JW. Microcomputer analyses of performance on a portable, simple visual RT task during sustained operations. Behav Res Methods Instrum Comput 1985;17:652-655. https://doi.org/10.3758/ BF03200977.

27. Basner M, Dinges DF. Maximizing sensitivity of the psychomotor vigilance test (PVT) to sleep loss. Sleep 2011;34:581-591. https://doi. org/10.1093/sleep/34.5.581.

28. Lim J, Dinges DF. Sleep deprivation and vigilant attention. Ann N Y Acad Sci 2008;1129:305-322. https://doi.org/10.1196/annals.1417.002.

29. Reitan RM. Validity of the Trail Making Test as an indicator of organic brain damage. Percept Mot Skills 1958;8:271-276. https://doi.org/10.2466/ pms.1958.8.3.271.

30. Stroop JR. Studies of interference in serial verbal reactions. J Exp Psychol 1935;18:643-662. https://doi.org/10.1037/h0054651.

31. Lezak M. Neuropsychological assessment. 3rd ed. New York: Oxford University Press, 1995.

32. Kim CY, Kim SY. Neuropsychology of attention. Sleep Med Psycho- 
physiol 1999;6:26-31.

33. Son KH, Kim SG, Jin YW, et al. Daytime sleepiness and fatigue in male adults in relation to shift work. Korean J Occup Environ Med 2005;17: 199-207. https://doi.org/10.35371/kjoem.2005.17.3.199.

34. Fitzpatrick JM, While AE, Roberts JD. Shift work and its impact upon nurse performance: current knowledge and research issues. J Adv Nurs 1999;29:18-27. https://doi.org/10.1046/j.1365-2648.1999.00861.x.

35. Kim JY. A study on the safety accidents by shift systems. Korean J Occup Environ Med 1996;8:330-339. https://doi.org/10.35371/kjoem.1996.8.2.330.

36. Akerstedt T. Psychological and psychophysiological effects of shift work. Scand J Work Environ Health 1990;16 Suppl 1:67-73. https://doi. org/10.5271/sjweh.1819.

37. Jeong JL, Kwon HM, Kim TH, Choi MR, Eun HJ. Effects of perceived stress, sleep, and depression on resilience of female nurses in rotating shift and daytime fixed work schedules. Sleep Med Psychophysiol 2019; 26:111-124. https://doi.org/10.14401/KASMED.2019.26.2.111.

38. Garbarino S, Guglielmi O, Puntoni M, Bragazzi NL, Magnavita N. Sleep quality among police officers: implications and insights from a systematic review and meta-analysis of the literature. Int J Environ Res Public Health 2019;16:885. https://doi.org/10.3390/ijerph16050885.

39. Rouch I, Wild P, Ansiau D, Marquié JC. Shiftwork experience, age and cognitive performance. Ergonomics 2005;48:1282-1293. https://doi. org/10.1080/00140130500241670.

40. Sakai K, Temmyo Y, Shindo H, Watanabe A, Saito H, Saito Y. A questionnaire study on shift systems of hospital nurses and measures. J Sci Labour 1985;61:167-205

41. Purnell MT, Feyer AM, Herbison GP. The impact of a nap opportunity during the night shift on the performance and alertness of 12-h shift workers. J Sleep Res 2002;11:219-227. https://doi.org/10.1046/j.13652869.2002.00309.x.

42. Sasaki T, Kikuchi Y, Shindo E. The effects of napping in a night duty taken by hospital nurses (III). Jpn J Ergon 1993;29:223-230. https://doi. org/10.5100/jje.29.223

43. Bonnet MH, Arand DL. Impact of naps and caffeine on extended nocturnal performance. Physiol Behav 1994;56:103-109. https://doi. org/10.1016/0031-9384(94)90266-6.

44. Takeyama H, Kubo T, Itani $\mathrm{T}$. The nighttime nap strategies for improving night shift work in workplace. Ind Health 2005;43:24-29. https:// doi.org/10.2486/indhealth.43.24.

45. Lichstein KL, Stone KC, Donaldson J, et al. Actigraphy validation with insomnia. Sleep 2006;29:232-239. https://doi.org/10.1093/sleep/29.2.232. 